\title{
LPG/CNG Gas Leakage Detection System with GSM Module
}

\author{
Alan M John ${ }^{1}$, Bhavesh Purbia ${ }^{2}$, Ankit Sharma ${ }^{3}$, Mrs. A.S Udapurkar ${ }^{4}$ \\ Students, Department of Electrical Engineering, NBN Sinhgad School of Engineering, Savitribai Phule University, \\ Pune, India ${ }^{1,2,3}$ \\ Professor Department of Electrical Engineering, NBN Sinhgad School of Engineering, Savitribai Phule University, \\ Pune, India ${ }^{4}$
}

\begin{abstract}
The Gas leakage is one of the big problems with industrial sector, residential milieu and gas functioning vehicles like CNG (Compressed Natural Gas) buses, cars etc. One of the contraceptive methods to stop accidents associated with the gas leakage is to install a gas leakage detection device at vulnerable places. The system detects the leakage of the LPG using a gas sensor and uses the GSM to alert the person about the gas leakage via SMS. When the concentration of LPG in air exceeds a certain level, the sensor senses the gas leakage and the output of the sensor goes LOW. The detection is done by the gas sensor, through the microcontroller the LED and buzzer are turned ON simultaneously. An alert is provided to the user, sending an SMS to the programmed mobile number.
\end{abstract}

Keywords: IC555, Opto coupler, MOSFET, Marx generator.

\section{INTRODUCTION}

There are numerous answers for fireplace accidents that agencies continually endorse. Smoke detectors, hearth alarms, hearth extinguishers and sprinklers are examples of those gadgets.

On reflection, those devices can also alert or prevent the unfold of fire but they do not save you hearth injuries, and that alone is a main downside already.

This have a look at makes a speciality of the LPG fuel and the way to save you it from causing greater injuries. There's a want to build a system that aids people's negligence of their surroundings even as stopping the begin of conflagration. The device also implements a shut-off mechanism which acts as the first line of defence inside the prevention of the coincidence ought to there be an absence of individual inside the residence.

Liquefied Petroleum fuel is constituent of Butane and Propane gases, which can be distinctly inflammable in nature. The LPG is an odorless gasoline and hence the addition of Ethanethiol allows it to show case a smell throughout its leakage. An ideal gasoline sensor may be used to feel the leakage of an LPG from cars, industries, homes and different residential regions. If there is a leakage of LPG, we will effortlessly perceive by using its concentration through the gasoline sensor and by using upward push in temperature. The LPG is broadly used for home functions such as boiling, heating and cooking. some human beings can also have a low sense of scent and in such instances they'll now not be able to respond for the gasoline concentration present.

Consequently, a protection primarily based LPG detection system is crucial to provide alertness, protection and protection from any harmful fuel leakage injuries. The incidents which include Kumbakonam and Bhopal fuel tragedy were the examples of the arena's worst fuel leakage injuries. This leakage detection gadget detects the fuel leakage and additionally stops the gasoline deliver together with an alarm and a GSM alerts the required person. The fuel sensor we used right here identifies the toxic gases other than LPG and its voltage goes LOW when there's a leakage of any toxic fuel. LOW signal is despatched to a microcontroller which in flip sends those alerts to the buzzer hence, rising an alarm. After some milliseconds, the fuel leakage message is sent to the user identified mobile range thru GSM module.

\section{PROPOSED METHOD}

We purpose a system to come across LPG fuel leakage situations and offer a security alert to supposed customers. We right here endorse to build the gadget the use of a MQ5 gas detection sensor.

If the LPG sensor senses any gas leakage from storage, gas sensor is going stumble on it this sign is monitored by using the microcontroller and it'll perceive the gasoline leakage. Now the microcontroller is turn on LED and buzzer. After few milliseconds put off, microcontroller instructions driving force circuitry for exhaust fan to turn the fan on to release 
the gasoline outdoor from the room and concurrently microcontroller commands every other circuitry a relay circuitry to shut the fuel knob.

In our proposed machine we designed two motive force circuitry one to power motor to close knob. And any other is relay circuitry in which relay is used to switched on and rancid for exhaust fan. Microcontroller is programmed by using embedded $c$ language. It's far the complete control of the task. It controls the Exhaust fan, LED, Buzzer and when LPG leak takes place. The enter/ output ports of the microcontroller is used for this.

\section{BLOCK DIAGRAM}

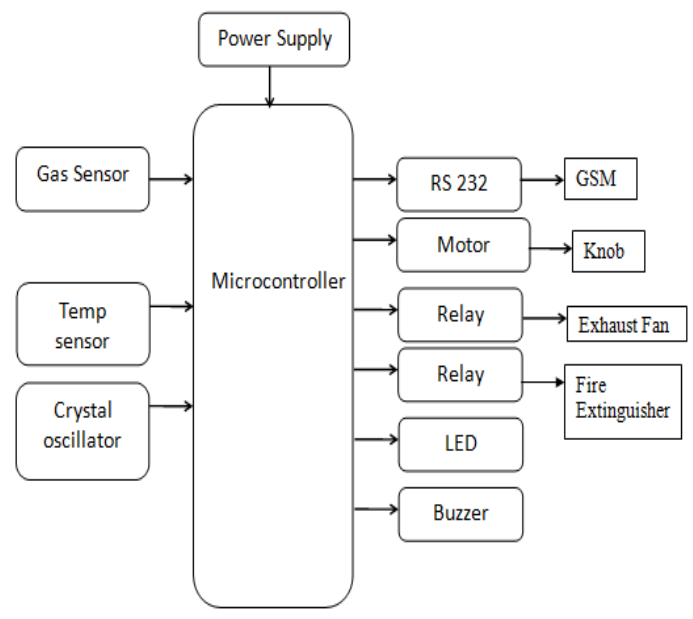

Fig.1 Block Diagram of LPG/CNG gas detection

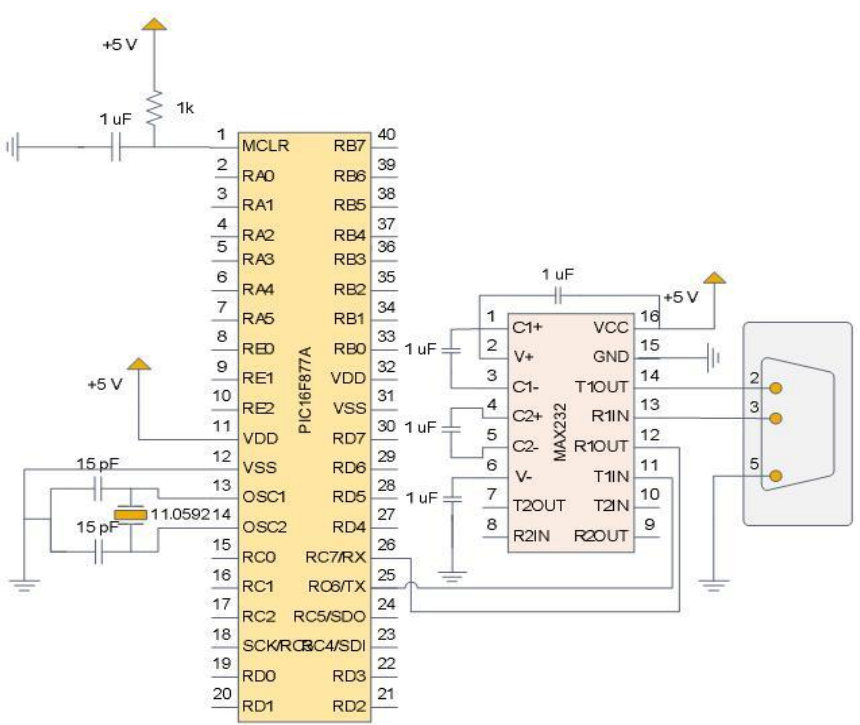

Fig. 2 Interfacing Of Microcontroller with MAX232

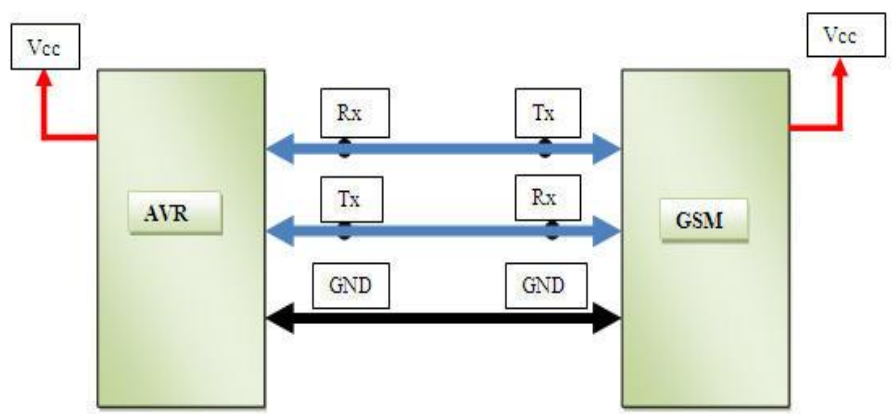

Fig.3: Connection with Microcontroller and GSM Module 


\section{COMPONENTS OF SYSTEM}

LPG concentration:

MQ5 sensor module is responsible for detecting LPG concentration in the controlled environment.

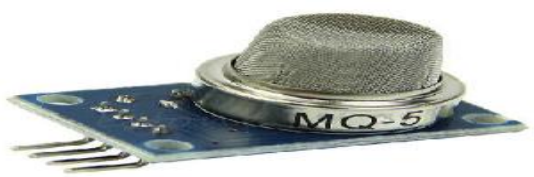

Fig.4 MQ5 gas sensor

Temperature sensor:

LM35 Temperature sensor with 3 pins: $\mathrm{V}$ in, $\mathrm{V}$ out and Gnd. The $\mathrm{V}$ out pin is directly connected to the microcontroller's analog input.

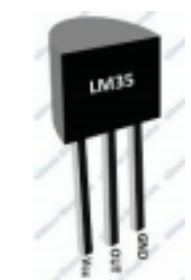

Fig. Temp. Sensor

\section{GSM (SIM900D):}

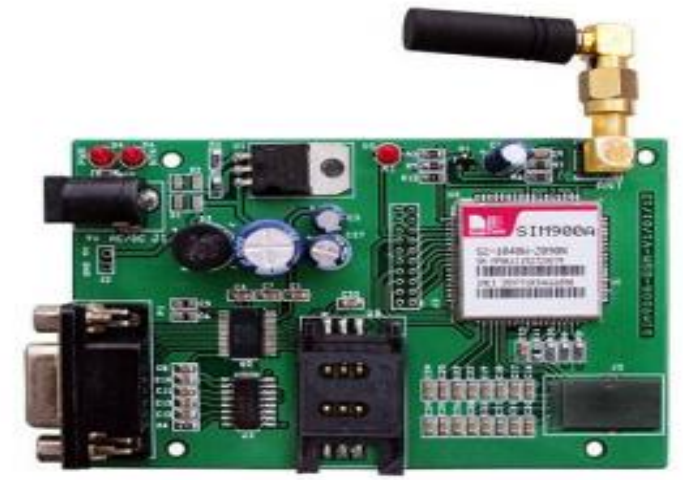

Fig. GSM SIM900D

Notification happens through SMS offerings The GSM module block is in charge of processing the information while the sensors start to stumble on a presence of gasoline within the environment his facts then is exceeded to the GSM/GPRS module which utilizes SIM900D mobile engine and passes the message to the cellular consumer assigned.

\section{Gasoline Knob:}

The execution of actions in diffusing the concentration of LPG and preventing it right from its source manifest thru the use of a knob.

LED:

While LED is sparkling, this suggests the leakage of LPG gas. it's miles 2 V DC operated LED.

PIC16F877 Microcontroller:

This powerful (200 nanosecond coaching execution) but smooth-to-application (simplest 35 unmarried phrase instructions) CMOS FLASH-primarily based eight-bit microcontroller packs Microchip's powerful \%® structure into an forty- or 44-pin bundle and is upwards well matched with the PIC16C5X, PIC12CXXX and PIC16C7X gadgets. 
The PIC16F877A functions 256 bytes of EEPROM statistics memory, self programming, an ICD, 2 Comparators, eight channels of 10-bit Analog-to-virtual (A/D) converter, 2 seize/evaluate/PWM capabilities, the synchronous serial port can be configured as either three-twine Serial Peripheral Interface (SPI ${ }^{\mathrm{TM}}$ ) or the two-cord Inter-included Circuit $\left(\mathrm{I}^{2} \mathrm{C}^{\mathrm{TM}}\right.$ ) bus and Asynchronous Receiver Transmitter (USART). All of those features make it ideal for extra superior stage A/D programs in automobile, commercial, appliances and purchaser packages. Ceramic is class of artifical material, which poses piezo electric effect and is widely used to make disc, the coronary heart of piezo buzzer. Whilst subjected to an alternating electric powered subject they stretch or compress, according with the frequency of the sign thereby producing sound. The piezo buzzer produces sound primarily based on opposite of the piezoelectric effect. The generation of strain version or pressure by using the software of electric potential across a piezoelectric material is the underlying precept. These buzzers can be used alert a consumer of an occasion corresponding to a switching motion, counter signal or sensor enter. They are also used in alarm circuits

Exhaust Fan:

This is used to send out the LPG to space and then the concentration of LPG is reduced.

\section{Buzzer:}

When buzzer is blowing, this indicates the leakage of LPG gas. It is $12 \mathrm{~V}$ DC operated buzzer. Piezo buzzer is an electronic device commonly used to produce sound. Light weight, simple construction and low price make it usable in various applications like car/truck reversing indicator, computers, call bells etc. Piezo buzzer is based on the inverse principle of piezo electricity discovered in 1880 by Jacques and Pierre Curie. It is the phenomena of generating electricity when mechanical pressure is applied to certain materials and the vice versa is also true. Such materials are called piezo electric materials. Piezo electric materials are either naturally available or manmade.

\section{WORKING PRINCIPLE}

The sensing material in TGS gas sensors is metal oxide, most typically $\mathrm{SnO}$. When a metal oxide crystal such as $\mathrm{SnO} 2$ is heated at a certain high temperature in air, oxygen is adsorbed on the crystal surface with a negative charge. Then donor electrons in the crystal surface are transferred to the adsorbed oxygen, resulting in leaving positive charges in a space charge layer. Thus, surface potential is formed to serve as a potential barrier against electron flow.

Inside the sensor, electric current flows through the conjunction parts (grain boundary) of $\mathrm{SnO} 2$ micro crystals. At grain boundaries, adsorbed oxygen forms a potential barrier which prevents carriers from moving freely. The electrical resistance of the sensor is attributed to this potential barrier. In the presence of a deoxidizing gas, the surface density of the negatively charged oxygen decreases, so the barrier height in the grain boundary is reduced. The reduced barrier height decreases sensor resistance.

\section{Working Model Working}

Regulated power supply is fed to MCLR Pin of PIC16F877 Microcontroller which is also supplied with crystal oscillator frequency (i.e.) from OSC 1 and OSC 2 for the working of the microcontroller. With the help of step down transformer of $230 \mathrm{~V}$ AC primary to $0-12 \mathrm{~V}, 500 \mathrm{~mA}$ secondary power supply is taken from main supply. Full-wave rectifier and a capacitor filter provide the output voltage and then fed to 5-volt regulator (LM7805) whose output is used as power supply for IC's and microcontroller. Furthermore, temperature sensor and gas sensor is connected to the microcontroller. The Complete Connection Diagram consists of the Microcontroller Circuit, GSM Module, Power Supply, GAS Sensor Module and Exhaust Fan. The Power Supply is fed to the GSM Module. The output of the sensor goes low as soon as the MQ-5 Gas Sensor senses any gas leakage from the storage. This is detected by the microcontroller and the LED \& buzzer are turned ON. After the delay of a few milliseconds, the exhaust fan is also turned ON for throwing the gas out and the microcontroller continues sending message as "GAS LEAKAGE" to a predefined mobile number using GSM Module.

\section{ADVANTAGES \& DISADVANTAGES:}

There are various advantages and disadvantages of using LPG Gas detection system/kit using GSM module installed at residential homes/industries etc. They are discussed below.

\section{Advantages}

1. Low cost

2. Low power consumption

3. High accuracy

4. It also detects alcohol so it is used as liquor tester.

5. The sensor has excellent sensitivity combined with a quick response time. 
Disadvantages

1. No prevention of fires possible with kit.

2. Applicable only as an indicator/alarming device.

3. It works only when at $5 \mathrm{~V}$ power supply is given.

4. Its sensitivity depends on Humidity and temperature.

5. It is a little sensitive to smoke.

\section{CONCLUSION AND FUTURE SCOPE}

For the first stage project presentation the required research work has been completed and the validation of project has been proved. Hence it can be said that the aim of the project "LPG Gas Detection System Using GSM Module" can be achieved successfully. The further designing and fabrication of the working model will be completed by February 2016. After which the different experiments will be conducted for efficiency improvement.

\section{REFERENCES}

[1] T. Murugan, A. Periasamy and S. Muruganand, "Embedded Based Industrial temperature monitoring system using GSM", International Journal of computer applications.

[2] V. Ramya and B. Palaniappan, "Embedded system for Hazardous gas detection and Alerting," in Proc. of International Journal of Distributed and parallel system (IJDPS), vol. 3, no. 3, May 2012

[3] L. Solis, Y. Li and L. B. Kishs, "Fluctuation-Enhanced Multiple-gas sensing by Commercial Taguchi Sensor,"IEEE Sensor Journal, vol. 5, no. 6, Dec 2005.

[4] H. G. Rodney Tan, C. H. Lee and V. H. Mok, "Automatic Power Meter Reading System Meter Reading Using GSM Network," in Proc. of the 8 Th International Conference.

[5] H. Huang, H. Bainand S. Zhu, “A Greenhouse Remote Monitoring System Based on GSM," in Proc. of IEEE International Conference on information management.

[6] A Jain, D. Kumar and J. Kedia, "Design and development of GSM based energy Meter, "International Journal of Computer Application, vol. 47, no. 12, June 2012 .

[7] S. Shinde, S. B. Patil and A. J. Patil, "Development of movable gas tanker leakage detection using wireless sensor network based on embedded system," International Journal of Engineering Research and Application(IJTERA), vol. 2, pp. 1180-1183, Nov.-Dec. 2012.

[8] Geronimo, "Gas leak, not bomb, caused Two Seren blast," GMA Network, 7 June 2013. http://www.gmanetwork.com/news/story/311810/news/metromanila/gasNot-bomb-caused-two-serendra-blast-mar-roxas.

[9] NSO, "Philippines in Figures; 2014" http://web0.psa.gov.ph/sites/default/files/attachments/gad/article/2013 \%20Annual\%20Report_Region\%20I_final.pdf.

[10] DOH, "Leading causes of mortality "; 16 April 2013. http://www.doh.gov.ph/node/198.html. 